\title{
Inadvertent Overdose of Low-Molecular- Weight Heparin in an Elderly Patient with Deep Vein Thrombosis and Acute Kidney Injury
}

\author{
Abdullah S Al Saleh and David Anderson
}

\section{INTRODUCTION}

$\mathrm{L}$ ow-molecular-weight heparin (LMWH) is commonly used to treat deep vein thrombosis. The dose is usually based on the patient's body weight, and for some preparations the manufacturer recommends a daily maximum dose. Unlike the situation for unfractionated heparin, no effective antidote is available for LMWH overdose. Protamine sulphate neutralizes the anticoagulant effect of unfractionated heparin, but it is only partially effective against LMWH. Protamine sulphate is composed of polypeptides that bind heparin to form a stable, inactive complex that inhibits the anti-factor IIa effect of LMWH, ${ }^{1}$ but the effect on anti-factor $\mathrm{Xa}$ is only partial, ${ }^{2,3}$ reaching up to $74 \% .^{4}$

Despite the frequent use of LMWH, there are few descriptions of management strategies for LMWH overdoses. Furthermore, most case reports of LMWH overdose have involved patients who were relatively young. ${ }^{1-3,5-7}$ To the authors' knowledge, the current article is the first report of LMWH overdose in a patient over 80 years of age.

\section{CASE REPORT}

An 85-year-old woman with a medical history of hypothyroidism, hypertension, and a single transient ischemic attack presented to her local emergency department with a 3-day history of pain and swelling of the right leg.* Proximal deep vein thrombosis was diagnosed by ultrasonography, although no major risk factors for deep vein thrombosis were identified. LMWH treatment (dalteparin, $200 \mathrm{U} / \mathrm{kg}$ or $22000 \mathrm{U}$ daily, administered subcutaneously) was started in the emergency

$\bar{*}$ The patient gave informed consent for publication of this report. department. This dose exceeded the manufacturer's recommended maximum daily dose of 18000 units. Warfarin $10 \mathrm{mg}$ was also initiated on the day of diagnosis. The patient was discharged home in stable condition with a plan for injections of dalteparin to be performed by a home care nursing service. On the second day of treatment, the patient was mistakenly given 82500 units of dalteparin from a multidose vial of medication. The nurse who was administering the medication recognized the error almost immediately, and the patient was sent to a tertiary care hospital for further management.

Upon initial assessment in the emergency department, the patient's vital signs were stable, and she had no symptoms or signs of overt bleeding. At that time, the white blood cell count was $12 \times 10^{9} / \mathrm{L}$ (normal range $4.5-11 \times 10^{9} / \mathrm{L}$ ) , hemoglobin was $127 \mathrm{~g} / \mathrm{L}$ (normal range 120-160 g/L), and the platelet count was $247 \times 10^{9} / \mathrm{L}$ (normal range $150-350 \times 10^{9} / \mathrm{L}$ ). Serum creatinine was $189 \mu \mathrm{mol} / \mathrm{L}$ (normal range 49-90 $\mu \mathrm{mol} / \mathrm{L}$ ), with an estimated glomerular filtration rate of $33 \mathrm{~mL} / \mathrm{min}$ (normal range for age $\geq 70 \mathrm{~mL} / \mathrm{min}$ ). The activated partial thromboplastin time (aPTT) was $112 \mathrm{~s}$ (normal range 26-38 s), international normalized ratio (INR) was 1.4 (normal range 0.8-1.2), and the anti-factor Xa (anti-Xa) level was $3.6 \mathrm{U} / \mathrm{mL}$ (therapeutic range while on LMWH 0.5-1.2 U/mL).

Because of concerns about the risk of bleeding, protamine sulphate was administered intravenously, starting with a 50-mg bolus given over $30 \mathrm{~min}$, followed by continuous infusion over a total of $13 \mathrm{~h}(50 \mathrm{mg} / \mathrm{h}$ for $6 \mathrm{~h}$, then $30 \mathrm{mg} / \mathrm{h}$ for an additional $7 \mathrm{~h}$ ). The warfarin was discontinued, and the patient was given vitamin K $10 \mathrm{mg}$ and prothrombin complex concentrate 5000 IU, both administered intravenously. Over the next $13 \mathrm{~h}$, there was a steady decline in aPTT and anti-Xa toward normal levels (Table 1). There was no evidence of overt bleeding or changes 
This single copy is for your personal, non-commercial use only.

For permission to reprint multiple copies or to order presentation-ready copies for distribution, contact CJHP at cjhpedit@cshp.ca

Table 1. Coagulation Parameters after Administration of Dalteparin*

\begin{tabular}{|c|c|c|}
\hline Time after arrival (h)† & aPTT (s)‡ & $\begin{array}{l}\text { Anti-Factor } \\
\mathrm{Xa}(\mathrm{U} / \mathrm{mL}) \S\end{array}$ \\
\hline$\overline{0}$ & 115 & 3.6 \\
\hline 1 & 68 & 3.04 \\
\hline$\underline{9}$ & 41 & 1.36 \\
\hline \multicolumn{3}{|c|}{$\begin{array}{l}\text { aPTT = activated partial thromboplastin time. } \\
\text { *Dose of dalteparin: } 82500 \mathrm{U} \text {. } \\
\text { †lt was not possible to determine the interval between } \\
\text { injection of dalteparin (which occurred in the patient's home) } \\
\text { and arrival in the emergency department. For the purposes of } \\
\text { this table, time zero was shortly after arrival in the emergency } \\
\text { department. } \\
\text { ¥The normal range for aPT is } 26-38 \mathrm{~s} \text {. } \\
\S \text { The therapeutic range for anti-factor Xa is } 0.5-1.2 \mathrm{U} / \mathrm{mL} \text {. }\end{array}$} \\
\hline
\end{tabular}

in hemoglobin during her 36-h stay in the emergency department. She was discharged home with a prescription for dalteparin 18000 units to be injected by the nurse using prefilled syringes, starting the next day. Warfarin was also resumed. She received a total of 6 months of anticoagulant therapy, and her leg symptoms resolved.

\section{DISCUSSION}

LMWH is an effective anticoagulant, but its use is associated with a risk of bleeding that is magnified in cases of overdose. Excretion of LMWH is primarily renal. Elderly patients may be particularly susceptible to the risks of bleeding with LMWH overdose, given that glomerular filtration rates are commonly reduced and bleeding risk with anticoagulation is increased in older patients. ${ }^{8-11}$

To our knowledge, the patient described here is the oldest person to have received a massive LMWH overdose. The oldest patient previously described in the literature was a 69-year-old woman with tinzaparin overdose. ${ }^{12}$ The current patient received more than 4 times the manufacturer's recommended dose of dalteparin. The significance of the overdose was increased by the patient's impaired renal clearance. Given the potential risk of bleeding, a 13-h continuous infusion of protamine sulphate was administered, and coagulation parameters were monitored. Fortunately, this patient did not experience bleeding complications, and anticoagulation with dalteparin and warfarin was successfully resumed.

This case is important for 2 reasons: the patient received one of the highest doses of LMWH ever reported, and she was an elderly patient with impaired renal function. One contributing risk factor for overdose in this case was the use of a multidose vial for administration of the LMWH. The use of prefilled syringes may be a better option to avoid dose calculation errors.

Currently, there is no consensus about the optimal management of LMWH overdose. Some guidelines recommend the use of protamine sulphate, particularly if there is major bleeding.
Previous case reports and case series have reported good outcomes with administration of protamine sulphate to patients with LMWH overdose. ${ }^{1,3,13}$ However, there have also been reports of supportive management of LMWH overdose without administration of protamine sulphate. ${ }^{5,6}$ Definitive evidence-based guidelines on dosing of protamine sulphate and frequency of monitoring are lacking. In its guidelines, the American College of Chest Physicians suggests using $1 \mathrm{mg}$ of protamine sulphate per 100 anti-Xa units of LMWH in the first $8 \mathrm{~h}$ and another $0.5 \mathrm{mg}$ per 100 anti-Xa units if the bleeding continues. ${ }^{13}$ The patient in this case received a total of $560 \mathrm{mg}$ of protamine sulphate, which is less than the dose recommended by the American College of Chest Physicians (calculated at $825 \mathrm{mg}$ ). This lower dose reflected the patient's age and the absence of overt bleeding. Protamine sulphate is recognized as only partially neutralizing LWMH, which may relate in part to the degree of sulphation of the compound. ${ }^{4}$

Serious adverse events related to protamine sulphate are uncommon. Anaphylaxis causing death occurs in about $0.2 \%$ of patients. ${ }^{14}$ Other adverse effects include gastrointestinal upset (nausea and vomiting), hypotension, and hemorrhage.

In the largest retrospective case series, van Veen and others ${ }^{15}$ described a cohort of 17 patients receiving the LMWH enoxaparin, in whom reversal was needed because of bleeding or surgery. Protamine sulphate use was associated with a reduction in bleeding; however, 3 of the patients continued to experience bleeding or rebleeding, despite administration of protamine. Protamine sulphate had minimal effect on reducing anti-Xa levels in these patients.

This case had some limitations. It is not possible to draw definitive conclusions about the effectiveness of this therapeutic approach on the basis of a single case report, and the outcome of the case might have been equally satisfactory with observation and supportive care alone, as noted in some previous reports. ${ }^{5,6}$

\section{CONCLUSION}

There are no clear guidelines for management of LMWH overdose. Some clinicians prefer observation alone, whereas others attempt to reverse the anticoagulation with protamine sulphate. We elected to intervene with protamine sulphate because of the very large amount of LMWH administered, the advanced age of the patient, and the low estimated glomerular filtration rate, with recognition that this agent only partially reverses the anticoagulant effect of LMWH. Fortunately, the patient recovered without further incident.

\footnotetext{
References

1. Odeberg J, Carlsson A, Hällsjö-Sander C, Agren A. A case series of five episodes of massive LMWH non-fatal self-induced overdose in a single patient. Thromb Res. 2012;129(5):668-70.

2. Chawla LS, Moore G, Seneff MG. Incomplete reversal of enoxaparin toxicity by protamine: implications of renal insufficiency, obesity, and
} 
low molecular weight heparin sulfate content. Obes Surg. 2004; $14(5): 695-8$

3. Wiernikowski JT, Chan A, Lo G. Reversal of anti-thrombin activity using protamine sulfate. Experience in a neonate with a 10-fold overdose of enoxaparin. Thromb Res. 2007;120(2):303-5.

4. Crowther MA, Berry LR, Monagle PT, Chan AK. Mechanisms responsible for the failure of protamine to inactivate low-molecularweight heparin. Br J Haematol. 2002;116(1):178-86.

5. Monte AA, Bodmer M, Schaeffer TH. Low-molecular-weight heparin overdose: management by observation. Ann Pharmacother. 2010;44 (11):1836-9.

6. Hasan K, Lazo-Langner A, Acedillo R, Zeller M, Hackam DG. Anticoagulant response after dalteparin overdose. J Thromb Haemost. 2010; $8(10): 2321-3$.

7. Bjornaas MA, Jacobsen EM, Jacobsen D. Nonfatal self-poisoning with LMW heparin and the use of antidote. Thromb Res. 2010; 126(5):e403-5.

8. Bauersachs RM. Use of anticoagulants in elderly patients. Thromb Res. 2012;129(2):107-15.

9. Nieto JA, Solano R, Ruiz-Ribó MD, Ruiz-Gimenez N, Prandoni P, Kearon $\mathrm{C}$, et al. Fatal bleeding in patients receiving anticoagulant therapy for venous thromboembolism: findings from the RIETE registry. J Thromb Haemost. 2010;8(6):1216-22.

10. Prandoni P, Trujillo-Santos J, Sanchez-Cantalejo E, Dalla Valle F, Piovella $\mathrm{C}$, Pesavento $\mathrm{R}$, et al. Major bleeding as a predictor of mortality in patients with venous thromboembolism: findings from the RIETE Registry. J Thromb Haemost. 2010;8(11):2575-7.

11. Trujillo-Santos J, Herrera S, Page MA, Soto MJ, Raventós A, Sanchez R, et al. Predicting adverse outcome in outpatients with acute deep vein thrombosis: findings from the RIETE Registry. J Vasc Surg. 2006; 44(4):789-93.
12. Balla I, Karafotias I, Christopoulos C. Intentional overdose with tinzaparin: management dilemmas. J Emerg Med. 2014;46(2):197-201.

13. Hirsh J, Bauer KA, Donati MB, Gould M, Samama MM, Weitz JI. Parenteral anticoagulants: American College of Chest Physicians evidence-based clinical practice guidelines (8th edition). Chest. 2008;133 (6 Suppl):141S-159S.

14. Nybo M, Madsen JS. Serious anaphylactic reactions due to protamine sulfate: a systematic literature review. Basic Clin Pharmacol Toxicol. 2008;103(2):192-6.

15. van Veen JJ, Maclean RM, Hampton KK, Laidlaw S, Kitchen S, Toth P, et al. Protamine reversal of low molecular weight heparin: clinically effective? Blood Coagul Fibrinolysis. 2011;22(7):565-70.

Abdullah S Al Saleh, MD, is a Medical Resident in the Department of Medicine, Dalhousie University, Halifax, Nova Scotia.

David Anderson, MD, FRCPC, is a Professor with the Department of Medicine, Division of Hematology, and is also Dean of the Faculty of Medicine, Dalhousie University, Halifax, Nova Scotia.

Competing interests: None declared.

\section{Address correspondence to:}

Abdullah Al Saleh

Department of Medicine

Dalhousie University

Room 483, 1276 South Park Street

Halifax NS B3H 2 Y9

e-mail: alsaleh-abdullah@hotmail.com

Funding: None received.

\section{ON THE FRONT COVER}

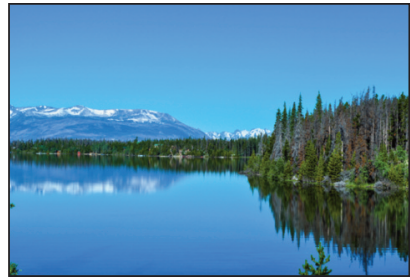

\section{Charlotte Lake, British Columbia}

CSHP member Sean Spina took this issue's cover photograph while relaxing in a wood fire-heated hot tub on the shores of Charlotte Lake, in the Chilcotin area of British Columbia. The Chilcotin is a relatively pristine area of the province, where the purity of the water, the colour of the trees, and the freshness of the air are second to none. Sean was in the midst of a summer vacation adventure with his family when he captured this scene. Sean is the Clinical Coordinator of Pharmacy Services at the Royal Jubilee Hospital in Victoria, British Columbia.

The CJHP would be pleased to consider photographs featuring Canadian scenery taken by CSHP members for use on the front cover of the journal. If you would like to submit a photograph, please send an electronic copy (minimum resolution $300 \mathrm{dpi}$ ) to cjhpedit@cshp.ca. 